\title{
Correction to: Assessment of Degradation of Sulfonylurea Herbicides in Water by Chlorine Dioxide
}

\author{
Marija V. Pergal • Igor D. Kodranov • Miodrag M. Pergal • Biljana P. Dojčinović • \\ Dalibor M. Stanković • Branka B. Petković • Dragan D. Manojlović
}

Published online: 3 September 2018

(C) Springer Nature Switzerland AG 2018

\section{Correction to: Water Air Soil Pollut \\ https://doi.org/10.1007/s11270-018- \\ 3947-2}

During typesetting, the image of figure 4 was also used in figure 5 . The mistake was discovered after the original article was published online.

The original article was updated by correcting figure 5 .

The online version of the original article can be found at https://doi.org/10.1007/s11270-018-3947-2

M. V. Pergal $(\bowtie) \cdot$ B. P. Dojčinović

Institute of Chemistry, Technology and Metallurgy, University of Belgrade, Njegoševa 12, Belgrade 11000, Serbia

e-mail: marija.pergal@gmail.com

I. D. Kodranov · M. M. Pergal · D. D. Manojlović

Faculty of Chemistry, University of Belgrade, Studentski trg

12-16, Belgrade 11000, Serbia

D. M. Stanković

The Vinca Institute of Nuclear Sciences, University of Belgrade, POB 522, Belgrade 11001, Serbia

B. B. Petković

Depatment of Chemistry, Faculty of Natural Science and Mathematics, University of Priština, Lole Ribara 29, Kosovska, Mitrovica 38220, Serbia

D. D. Manojlović

South Ural State University, Lenin prospekt 76,

454080 Chelyabinsk, Russia 